\title{
Heart regeneration is regulates by key micro RNAs from fish to mammals: what it can learned about the epicardial cells activation during the regeneration in zebrafish
}

\author{
Nicla Romano $\mathbb{1}^{1}$ and Marcello Ceci ${ }^{1}$
}

Zebrafish could be an interesting translational model to understand and improve the post-infarction trial and possible regeneration in mammals. The regenerative capacity in mammalian heart is maintained partially in neonatal life ${ }^{1}$ because are still switch-on some phylogenetic-conserved genes; while in adult, it seems to confined in replacing by a few of cardiomyocytes (CM) and by a large amount of fibroblasts ${ }^{2,3}$. In contrast, natural cardiac regeneration appears to be excellent in fish after an injury. In zebrafish, the cardiac environment created by cardiomyocytes, fibroblasts, and non-muscle cells after injury is believed to be critical in facilitating the regenerative response ${ }^{4}$. The epicardium-derived cells and the consequent epicardial cells (EPCs) are essential regulators since they respond to FGFs in both embryogenesis and regeneration processes. EPCs undergo to number of cellular modifications ${ }^{5,6}$ that is required to silenced by miRs that controlled the differentiation of the cells. This downregulation is a necessary event to activate the transition from epithelial to mesenchymal cells, such as cytoskeletal re-arrange and expression of hyaluronanmediated motility receptor, necessaries to move in the damage site $e^{7,8}$. In the heart several molecules are involved in the protein synthesis regulation ${ }^{9}$ where the miRs have a upstream actions. MiR1 and miR133 ( $\mathrm{a}$ and b) are involved in the activation of fibroblasts in producing $\mathrm{FGFs}^{10,11}$, as well as the hypertrophic response of epithelial and muscular cells after injury, to compensate for

\footnotetext{
Correspondence: Nicla Romano (nromano@unitus.it)

${ }^{1}$ Department of Ecological and Biological Sciences, University of Tuscia,

Viterbo, Italy
}

the loss-of-contractile tissue in mammals, as well as in zebrafish $^{9,12-14}$.

In the recent research edited in Cell Death and Dicovery $^{15}$, we have explored the time lapse of downregulation of miRs 133a, 133b, and miR1 during the regeneration trial in zebrafish, discovering that the downregulation occur already after $24 \mathrm{~h}$ post injury (hpi) and had being become critical during the next 48 hpi (Fig. 1). Moreover, by using laser microdissector method we have demonstrated that this downregulation occur differently in activated EPCs as compare the site of regeneration. Next to the evaluation of miRs expression, we have analysed the expression of embryonal molecules that are re-expressed during the regeneration process: Willm's Tumor factor 1 (WT1, that is a marker for activated EPCs cells); Heat Shock Protein 70 (HSP70, a chaperon molecule activated during the embryogenesis in a double function:, block the apoptosis and help in the folding/transport of neosynthesized proteins) and one of the cardiac Troponin complex (cTNT, factor T, is the molecule that adhere to the tropomyosin and is determinant for the correct contraction of the muscle cardiac fibers, it is early expressed and indirectly controlled by miR1) It is probable that the block of myogenic or hyperplastic role of miR1 is crucial in activating the regeneration process. miR133a is probably a key miR that can activate the epicardium because it showed a more significant downregulation already at 1 dpa. Again, the miR133b could be a key miR because of its direct control on the CTGF protein, necessary to regulate the transition in endocardial cells from epithelial to mesenchymal elements. The Fig. 1 give a synthesis of the 


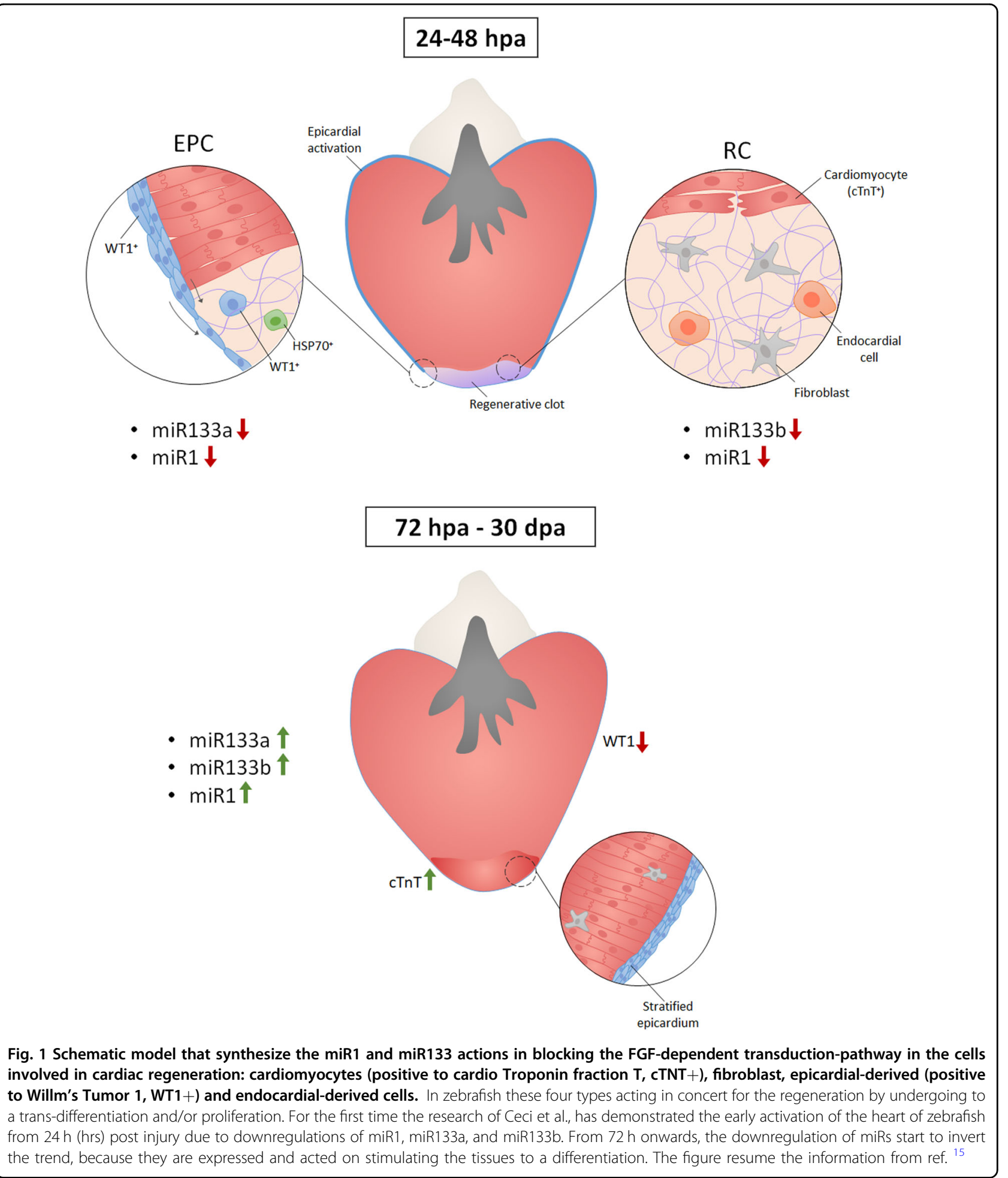

cited article and details are available in Ceci et al. ${ }^{15}$. This study provides key clues for the experimental early activation of pro-regenerative responses in the heart in zebrafish, and provides crucial insights for the development of therapies targeting heart disease.

\section{Acknowledgements}

We wish to thank you Dr. Bruna di Giacomo to have done the figure of this article.

Conflict of interest

The authors declare that they have no conflict of interest. 


\section{Publisher's note}

Springer Nature remains neutral with regard to jurisdictional claims in published maps and institutional affiliations.

Received: 10 April 2018 Accepted: 19 April 2018

Published online: 29 May 2018

\section{References}

1. Wu, C. \& Weidinger, G. Curr. Pathobiol. Rep. 2, 93-100 (2014).

2. Kikuchi, K. Stem Cell Res. 13, 542-555 (2014).

3. Chimenti, l. et al. Circ. Res. 106, 971-980 (2010).

4. Lepilina, A. et al. Cell 127, 607-619 (2006).
5. González-Rosa, J. M., Peralta, M. \& Mercader, N. Dev. Biol. 370, 173-186 (2012). 6. Ausoni, S. \& Sartore, S. J. Cell Biol. 184, 357-364 (2009).

7. Hall, C. L., Wang, C., Lange, L. A. \& Turley, E. A. J. Cell Biol. 126, 575-588 (1994).

8. Missinato, M. A., Tobita, K., Romano, N., Carroll, J. A. \& Tsang, M. Cardiovasc. Res. 107, 487-498 (2015).

9. Romano, N., Ricciardi, S., Gallo, P. \& Ceci, M. Biochem. Biophy. Res. Commun. 495, 601-606 (2017).

10. van Rooij, E. et al. Science 316, 575-579 (2007).

11. Wang, J., Karra, R., Dickson, A. L. \& Poss, K. D. Dev. Biol. 382, 427-435 (2013).

12. Sayed, D. \& Abdellatif, M. Physiol. Rev. 91, 827-887 (2011).

13. Liu, N. et al. Genes Dev. 22, 3242-3254 (2008).

14. Torella, D. et al. Cir. Res. 109, 880-893 (2011).

15. Ceci, M. et al. Cell Death Discov. 4, 41-53 (2018). 